\title{
Intolerancia en tiempos de crisis: hacia una literatura transgresora en El sitio de los sitios de Juan Goytisolo
}

\author{
Intolerance in times of crisis: towards a transgressive \\ literature in El sitio de los sitios by Juan Goytisolo \\ Intolerância em tempos de crise: para uma literatura transgressora \\ em El sitio de los sitios (o local dos locais) de Juan Goytisolo
}

\section{Óscar Iván Useche}

URSINUS COLLEGE, ESTADOS UNIDOS

Doctor en Culturas latinoamericana e ibérica por la Universidad de

Columbia y profesor asistente en Ursinus College, Pennsylvania.

Entre sus últimas publicaciones se encuentran "Laureano

Calderón's Social Foundry: Industrial Imagination and Social

Prescription in Restoration Spain" (Fournal of Spanish Cultural

Studies, 2018) y "The Science of Science Education: Zoel García

de Galdeano, Mathematics Instruction, and the Progress of Spain"

(Decimonónica, 2017). Correo electrónico: ouseche@ursinus.edu 


\section{Resumen}

Este artículo propone entender la novela de Goytisolo como una respuesta cultural a la crisis de los modelos de racionalidad occidental. Se estudian las dinámicas de descomposición social de la globalización y la aparición dentro de este contexto de figuras marginales que buscan recuperar su capacidad transgresora mediante la reconquista del cuerpo y la apropiación del espacio urbano. Al trasladar al plano textual el memoricidio y la limpieza étnica como expresiones negativas de la modernidad, Goytisolo problematiza el papel del lector, del autor y de la novela como elementos esenciales en la representación literaria de la realidad.

Palabras clave: Goytisolo; globalización; Sarajevo; memoria histórica

\section{Abstract}

This paper proposes an understanding of Juan Goytisolo's novel El sitio de los sitios as a cultural response to the crisis of traditional Western models of rationality. The article focuses on the study of the dynamics of global social decomposition and the emergence of marginal figures seeking to recover their transgressive capacity through their bodies and the appropriation of urban space. By bringing memoricide and ethnic cleansing in the novel as negative expressions of modernity, Goytisolo questions the role of the reader, the author and the novel itself as essential elements in the literary representation of reality.

Keywords: Goytisolo; globalization; Sarajevo; historical memory

\section{Resumo}

Este artigo propõe entender o romance de Goytisolo como resposta cultural à crise dos modelos de racionalidade ocidental. Estudam-se as dinâmicas de decomposição social da globalização e aparecimento dentro deste contexto de figuras marginais que procuram recuperar sua capacidade transgressora mediante a reconquista do corpo e a apropriação do espaço urbano. Al transferir no plano textual o memoricídio e a limpa étnica como expressões negativas da modernidade, Goytisolo problematiza o papel do leitor, do autor e do romance como elementos essenciais na representação literária da realidade.

Palavras-chave: Goytisolo; globalização; Sarajevo; memória histórica 
Tras el sitio de Sarajevo, a comienzos de los años noventa, la consolidación de un nuevo orden global dejó en evidencia la persistencia generalizada de odios religiosos y raciales en apariencia irreconciliables. La rearticulación de las identidades nacionales dentro de este nuevo orden ha tendido a deteriorar las posibilidades de convivencia cultural mediante prácticas en las que se condena lo diferente, el otro. En este sentido, el conflicto bosnio no fue sino la repetición, la metáfora y la metonimia de todas las tensiones que el continuo flujo migratorio promueve y agudiza en el espacio de intercambio cultural de una economía globalizada. Este es el contexto en el que se articula la novela de Juan Goytisolo El sitio de los sitios (1995). Escrita después de las visitas del autor a Sarajevo durante el sitio de $1992,{ }^{1}$ la obra es el resultado de combinar su sensibilidad hacia la barbarie del conflicto bosnio con la memoria de eventos igualmente irracionales en España, como la expulsión de los judíos y árabes en los siglos XV y XVI y, más recientemente, la Guerra Civil.² El sitio de los sitios es a la vez una novela sobre un lugar entre muchos otros

1 Goytisolo se unió a diferentes intelectuales, entre los que se encontraban, entre otros, Susan Sontag, David Rieff y Annie Leibovitz, en una labor periodística y artística de denuncia pública con la que se intentó llamar la atención sobre el conflicto bosnio y sus repercusiones ideológicas dentro del paradigma intervencionista de las potencias militares occidentales. Debido a la parcialidad de los lineamientos políticos de estos escritores, su presencia como corresponsales de los trágicos eventos no estuvo libre de polémica. Goytisolo, por ejemplo, visitó Sarajevo en dos ocasiones, y como corresponsal del diario El País intentó señalar la forma irresponsable con la que la mayoría de medios cubría la que él consideraba la mayor demostración del fracaso de la racionalidad occidental.

2 La obra de Juan Goytisolo se caracteriza por una profunda preocupación por el lenguaje y por la oscilación del autor entre el distanciamiento y el compromiso político en el marco de autoritarismo y represión propios de la dictadura franquista. Esta permanente tensión entre dos miradas contrapuestas de la realidad puede verse en términos de reverencia y, simultáneamente, resentimiento por un pasado del que el escritor no puede escapar. En este proceso de indagación, Goytisolo se ha acercado a la experimentación literaria para retratar la angustia que produce la incesante búsqueda de significados en una sociedad fragmentada. De esta forma, en sus novelas los personajes mutan permanentemente y el tiempo de la narración se multiplica en un juego de destrucción y reelaboración de la Historia y la identidad españolas. Influido por la visión heterogeneizante de Américo Castro y situado en el exilio, Goytisolo adquiere una visión particular de los conflictos religiosos y étnicos y su obra constituye un intento de emancipación de la individualidad que se refleja en su forma de entender el cuerpo. Obras como la trilogía Señas de identidad (1966), Don fulián (1970) y fuan sin tierra (1975), las novelas Paisajes después de la batalla (1985), Las virtudes del pájaro solitario (1988) o los textos autobiográficos Coto vedado (1985) y En los reinos de taifa (1986) son claros ejemplos de esta visión. 
-Bosnia, España-, el lugar de los cercos, el cerco de los espacios, o el mayor de los asedios: el de la memoria. Los diferentes niveles narrativos propuestos por Goytisolo buscan borrar la frontera entre ficción y realidad y proponer un espacio en el que la crudeza de la historia desarticula la racionalidad mediante un asedio a la individualidad.

El recuento que hace Goytisolo en sus crónicas periodísticas y en la novela, tras sus dos visitas a Sarajevo, apenas logra capturar la brutalidad de un asedio que comenzó el 5 de abril de 1992 y se extendió hasta los últimos días de febrero de 1996. En casi cuatro años, la población tuvo que reinventar su forma de vida para sobrevivir a la progresiva destrucción de la ciudad. La indiferencia de los países europeos y de Estados Unidos ante esta situación avaló la noción de que la violencia y la agresión son consecuencias irremediables del progreso. Goytisolo no necesitó ser testigo de todo el sitio para hermanarse, como lo había hecho en otras ocasiones, con una población oprimida que veía, al igual que había ocurrido en España durante la Guerra Civil, cómo se desarticulaban todos los órdenes sociales. El texto de Goytisolo es entonces el recuento del impacto que esta indiferencia produce en un autor asediado por la memoria de un pasado cargado de intolerancia; una obra esencial para aproximarse a la conflictiva negociación social y cultural de las prácticas capitalistas que, dadas las condiciones de la crisis actual, mantiene su vigencia y el carácter urgente de su denuncia.

A nivel biográfico, el interés de Goytisolo por todo lo que implica una transgresión lo ha llevado a escribir textos que, como señala Bradley Epps, "are essays on the potentially transformative relation between language an the socio-political order" (1). En estas obras el lenguaje se convierte en una herramienta para subvertir la realidad, desacralizando las utopías de convivencia de una sociedad en la que los países, como señala el mismo autor, se ven "empujados por la comunidad internacional a renunciar a la sociedad interétnica y ciudadana, ese logro de la civilización" (Goytisolo, Cuaderno 136). Esta es justamente la situación que más conmueve la sensibilidad del escritor, quien ve en el sitio de Sarajevo la culminación de un proceso de deterioro de la racionalidad occidental, un tema que ya había sido central en varias de sus obras anteriores - particularmente después de su novela autobiográfica Coto Vedado (1985), construida a partir de la problematización del carácter de marginalidad que adquiere el otro dentro de cualquier tensión étnico-religiosa- ${ }^{3}$

3 Como anota Manuel Hierro: "Frente al discurso que borra las diferencias culturales, Goytisolo opta por el palimpsesto multiétnico, el texto babel donde conviven y se 
y que conecta su trabajo con las ideas de Américo Castro y los razonamientos cargados de pesimismo que caracterizaron a la Escuela de Frankfurt.

En este marco de violencia y destrucción de los espacios de individualidad y libertades fundamentales, la guerra no solo se convierte en la protagonista de la obra de Goytisolo, sino también en la gestora de una narrativa en la que ficción y realidad se confunden, o como señala Antonio Monegal, "[l]a realidad se ha transmutado en ficción: el cuento de horror de nuestra existencia diaria!"' (162). La amenaza latente sobre la libertad de expresión, entendida en su contexto más amplio y articulada desde la visión de un autor convencido de las posibilidades de una sociedad fundada en la tolerancia, progresivamente reduce los espacios de participación del otro, relegando al espectro de lo privado toda posibilidad de confrontación contra el orden impuesto de las estructuras de poder. ${ }^{4}$ En este contexto, el otro se convierte en un extranjero que amenaza la misma sociedad a la que pertenece y la transgresión se hace necesaria para subvertir este contrasentido. Dentro del orden jerárquico que se crea alrededor de esta dinámica, el transgresor adquiere un carácter mesiánico, siendo una especie de héroe que intenta recuperar la capacidad de expresión y la movilidad en un orden social entregado a los excesos del capitalismo.

La intervención del aparato estatal para contener cualquier intento de contravención se extiende a todos los espacios vitales. En este sentido, la figura del defecador, central en el Sitio de los sitios, responde a la necesidad de recuperar las posibilidades trasgresoras que subyacen en el último reducto de individualidad: el cuerpo. Libre de los lineamientos que avalan la guerra como solución a las tensiones y ansiedades que producen las diferencias raciales y religiosas, el transgresor, a través del control sobre su cuerpo, se enfrenta a la colonización de un sistema que articula la oposición al "otro"

entienden los diferentes Goytisolo anteriores al 'desmembrado y hecho trizas' de Paisajes, el indeterminado pajarillo de Las virtudes del pájaro, o el muerto de La cuarentena, y que, sin duda, todos tienen las marcas mentales y vitales, la proyección textual del Goytisolo construido -escrito e inscrito- de Coto vedado" (151).

4 Para Marco Kunz, Goytisolo se ve también afectado por la intolerancia totalitaria de la mayoría de Estados contemporáneos y particularmente sus efectos en el sitio de Sarajevo, pues son "[t]endencias que a él [Goytisolo] lo amenazan directamente como individuo e intelectual que cree en el mestizaje, el cosmopolitismo, la tolerancia en un Estado laico y una sociedad pluralista y multicultural que los bombardeos de los sitiadores intentan destruir" (214). 
mediante el asedio. ${ }^{5}$ El defecador, entonces, es simultáneamente transgresor y extranjero: por una parte sus acciones lo convierten en un portavoz de la inconformidad, y, por otra, su reclamo de lo corporal lo margina de la sociedad asociándolo con lo que está fuera de la norma.

Julia Kristeva en su ensayo "Strangers to Ourselves" (1991) señala cómo el miedo al otro evoluciona como parte de una crisis subjetiva de lo ético y lo religioso (265). El carácter místico del transgresor es pues condición indispensable para que se consolide el aspecto religioso por el cual es segregado. El defecador es, por tanto, un profeta que se construye paso a paso, tanto en la obra de Goytisolo, como en la sociedad que lo desprecia pero lo necesita; es un infractor que "se desarrolla literariamente sobre la imagen del pensador ácrata" (Ruiz 161). Partidario de la supresión de toda autoridad, el defecador se opone abiertamente al nuevo orden global, una estructura de distribución del poder y la riqueza en la que el capitalismo ha creado sus propios vertederos, lugares simbólicos en los que la civilización se deshace de su propia excrecencia, es decir, de aquellas categorías que no se acoplan a la estructura social: los otros. ${ }^{6}$ El problema con este nuevo orden, como dilucidan Michael Hardt y Antonio Negri, es su deseo de constituir una totalidad mediante la búsqueda constante de uniformidad (xiv). Esta homogeneidad se vuelve aún más problemática cuando va más allá de conciliar diferencias políticas y entra en el espectro de lo racial y lo religioso. Es precisamente en este punto de inflexión que la literatura funciona como una herramienta de subversión.

La realidad de las alineaciones geopolíticas en el marco homogeneizador del nuevo orden global, sin embargo, hace imposible cualquier ideal de convivencia. La xenofobia, por ejemplo, aparece como reacción al intento de que diferentes culturas compartan una misma visión de construcción de la identidad nacional. Según Stanley Black, en la evolución de los intereses narrativos de Goytisolo, "whose targets progressively widen out from a critique of the social realist novel and Spanish historiography to his ... engagement with the pernicious effect of global capitalism and the New World Order" (Fuan Goytisolo 10), se puede ver un interés por este problema en específico.

5 Esta colonización no se da en los términos tradicionales sino en el contexto en el que Paul Virilio define la endocolonización y exocolonización en su texto City of Panic (2005). En esta obra, el filósofo francés señala que al cerrarse el mundo a la migración todos empezamos a ser excluidos, idea que dialoga con las de Julia Kristeva en cuanto el miedo a encontrar al otro en nosotros mismos se exterioriza generalmente como un odio hacia lo diferente.

6 Acá se utiliza la misma metáfora que Daniel Castillo usa en su texto Vertederos de la postmodernidad: Literatura, cultura y sociedad en América Latina (2000). 
La obra del escritor se articula a partir del estado de excepción que instituye el nuevo orden para conciliar la heterogeneidad identitaria. Para Hardt y Negri, en los Estados modernos la excepción redefine lo que se entiende por racional (orden, paz, etc.), y una especie de endocolonización reformula las tensiones con el otro alrededor de las categorías de pureza, limpieza e higiene. ${ }^{7}$ De esta forma, el contacto permanente con el transgresor hace más evidentes las diferencias internas hasta producir la confrontación violenta. El asedio opera entonces como una forma de demarcar límites, de evitar el contacto, de impedir la proliferación de la enfermedad; y, al mismo tiempo, es una forma de destruir el sentido de individualidad, atentando, en lo físico, contra el cuerpo.

Este asedio de la modernidad a lo que está fuera de la norma es explorado hasta sus últimas consecuencias por Goytisolo en El sitio de los sitios; así, los personajes más representativos en la obra son aquellos que buscan resaltar el carácter heterogéneo de la identidad y se convierten en transgresores: seres marginales que viven sitiados por una sociedad que se empieza a derrumbar ante el conflicto religioso, habitantes que conforman "la Internacional de los excrementos, las heces apestosas del nuevo orden planetario!" (Goytisolo, El sitio 49). A partir de la forma en que la novela rearticula la crisis de lo racional poniendo en tensión la higiene y la contaminación como categorías de la modernidad, en lo que sigue me centraré en tres temáticas principales: en primer lugar, la figura del defecador como síntoma de la inestabilidad social que promueve la globalización; en segundo lugar, el asedio imaginado del barrio Le Sentier de la ciudad de París, que promueve la creación de una política de limpieza racial y de pureza de sangre (ius sanguinis), recreando, en múltiples sentidos, varios episodios de la historia pasada y reciente de España; y, por último, la idea de la destrucción de la memoria como estrategia para denunciar el triunfo de la higiene ideológica, étnica y religiosa sobre la individualidad y la diferencia. En El sitio de los sitios, Goytisolo problematiza la idea de civilización resaltando la prevalencia de la intolerancia como respuesta al miedo que produce lo que está fuera de la norma. A mi parecer, aunque la posición que asume el autor frente a la situación de Sarajevo como epítome del deterioro ideológico de occidente resulta necesaria y reveladora,

7 Para Bradley Epps la obsesión con la limpieza y su consecuente rechazo de lo abyecto es un tema central en la obra de Goytisolo y sirve para evocar 'a 'final solution' where hygiene has gone mad, eliminating the eliminated, burning ash, and realizing a dream of purity, perfection, and order" (165). 
en la novela subsiste una tendencia homogeneizante que puede verse en el gesto de sobreponer la realidad española a la tragedia bosnia. Este acto de ventriloquismo, sin embargo, exalta la capacidad del lenguaje como una herramienta transgresora y llama la atención sobre el papel de la literatura como medio de denuncia y lugar de resistencia en el contexto de una globalidad que se opone al bienestar de la sociedad.

Debido a que Juan Goytisolo es uno de los escritores contemporáneos más leídos y estudiados, la crítica ha abordado su trabajo desde múltiples y variados aparatos teóricos. Entre las lecturas de su obra abundan los análisis formales, el estudio de las tensiones de género e identidad y la revisión del conflicto islámico-cristiano en su narrativa. En general, la obra de Goytisolo se divide en dos periodos: el de autor neorrealista y el de escritor experimental. Sin embargo, es solo en el segundo, a partir de la publicación de Señas de identidad (1966), que cobran forma las que serán las problemáticas centrales de todo su trabajo. En la novela, parte de una trilogía de corte autobiográfico que se completa con las posteriores Don fulián (1970) y fuan sin tierra (1975), la cuestión de la identidad se reformula a partir del conflicto étnico-religioso, la globalización y la tensión entre la trasgresión homo-erótica y la sumisión a los poderes totalitarios. Como ocurre con El sitio de los sitos, el estudio de las novelas de Goytisolo ha tendido a centrarse en su complejidad estructural, señalando la tensión que estas plantean entre autor y autoridad. ${ }^{8}$ Igualmente, las aproximaciones críticas a la novela han revisado sus conexiones con el testimonio, la autobiografía, la recuperación de la memoria histórica y el impacto de la globalización y la migración. ${ }^{9}$ Si bien todos estos temas enmarcan la

8 Esta complejidad estructural es de gran significancia para el estudio de la obra de Goytisolo en cuanto, como indica Marco Kunz, "[e]n el nivel formal, la escritura de Goytisolo experimenta con técnicas de hibridismo, mestizaje, polifonía y plurilingüismo que crean una heterogeneidad análoga a la mezcla multicultural de los ambientes urbanos que el autor prefiere" (9).

9 Dentro de este marco crítico, vale la pena resaltar el trabajo de Stanley Black, fuan Goytisolo and The Poetics of Contagion: The Evolution of a Radical Aesthetic in the Later Novels (2001), en el que se propone su obra como una constante exploración estética ligada a una evidente preocupación social. Igualmente relevante es su posterior ensayo sobre El sitio, "The Author as Hero in the New World Order: The Power of Fictionality in Goytisolo's El sitio de los sitios" (2004), en el que se resalta la capacidad de intervención del artista dentro del nuevo orden global. En ambos trabajos se propone que la trasgresión y los intentos de Goytisolo por subvertir la narrativa son el resultado de la fuerte influencia de los postulados estructuralistas que recibió el autor durante su exilio en Francia. Justo esta misma influencia es la que liga la obra del autor con una reevaluación del mito como parte esencial de la construcción de la identidad, tema que también explora Abigail Lee Six en fuan Goytisolo: The Case for Chaos 
problemática sobre la que va a girar el análisis propuesto en este trabajo, ninguno de estos estudios se ha centrado en la tensión higiene-contaminación, el memoricidio y la limpieza étnica como símbolos de la intolerancia. Considero que en la novela estas situaciones representan una denuncia problemática de las prácticas homogeneizantes del capitalismo mundial, que se ve cuestionada en el intento de Goytisolo de equiparar la situación yugoeslava de principios de los noventa con el pasado de fanatismo religioso y racial español.

La transgresión y la subversión propuestas por Goytisolo en El sitio de los sitios dialogan con la tensión entre globalización y rechazo a la convivencia cultural. En ese contexto, los temas de la migración y la represión pueden retomarse para ver la forma en que la figura del defecador encarna estas inconsistencias. La idea de la otredad como transgresión permite así abordar la problemática del memoricidio y el sitio como estrategias de renegociación de la identidad. Acá el defecador opera como perfecto representante de la subversión de los espacios público y privado dado que la abyección de lo excremental y su confinación a la intimidad se revierten en el intento por recuperar el control sobre el cuerpo como símbolo de la individualidad. ${ }^{10}$

En "Powers of Horror: An Essay on Abjection", Julia Kristeva reelabora desde una perspectiva freudiana las ideas centrales de Georges Bataille sobre la transgresión. ${ }^{11}$ Para Kristeva, la construcción de la subjetividad se da desde

(1990) y Alison Ribeiro en su estudio fuan Goytisolo: The Author as Dissident (2005). Otro aspecto fundamental explorado por la crítica y que merece ser mencionado es el que tiene que ver con el cuerpo, el género y la transgresión, temas que Bradley Epps analiza exhaustivamente en su monografía Significance Violence: Oppression and Resistance in the Later Narrative of fuan Goytisolo (1996). La violencia que es vista desde lo político y lo sexual, o como espacio de marginalidad y singularidad es también central al análisis de Manuel Ruiz en su trabajo sobre El sitio de los sitios, Lector apud Goytisolo (1996), y que se complementa con las ideas que plantean Genaro Pérez en "La cuarentena y El sitio de los sitios de Juan Goytisolo: intertextualidad, creación y recreación autorial" (2002) y Marco Kunz en su texto fuan Goytisolo: Metáforas de la migración (2003).

10 El defecador en la novela de Goytisolo es un emblema de resistencia a la capacidad homogeneizadora de la globalización; un reclamo a la individualidad. En ese sentido, la lectura que hace Joshua Gunn del personaje en su estudio sobre el carácter subversivo de la escritura resulta muy acertada e ilustrativa. Para Gunn, "the Metro Defecator represents a figure who has regressed to embrace his anality as a way to resist transnational capitalists he resists imperial globalization $[\ldots]$ he resists imperial globalization by taking back his anus, celebrating the excesses of his own productive capacity and calling for others to do the same" (82).

11 La relación personal que Goytisolo mantuvo con el grupo Tel-Quel enriquece el diálogo teórico con Kristeva y la relectura de Bataille que propone la novela en el marco de la guerra 
un estado pre-edípico en el que el niño desarrolla un rechazo por su madre para integrarse al espacio simbólico del mundo exterior. Para garantizar esta transición, la sociedad ha creado una serie de regulaciones sobre el cuerpo en las que se enfatiza fundamentalmente su rechazo. En este principio de abyección subyacen ciertas estrategias de poder con las que se busca asegurar la estabilidad de la estructura social a través de su homogeneización. Esta es la misma problemática que aborda Guy Hocquenghem en su ensayo "Capitalism, the Family, and the Anus" (1993), en el que propone al homosexual como una figura transgresora que se convierte en amenaza para un orden social en el que lo privado y lo público se han construido para favorecer la estructura de la familia y perpetuar con esta el sistema capitalista. El miedo de la sociedad al poder transgresor del homosexual está en su imposibilidad reproductiva, condición relacionada directamente con la reversión del referente fálico y la consolidación del ano, ya no como reducto de la individualidad, sino como lugar de deseo colectivo. Es en este sentido que resulta relevante el análisis histórico que propone Dominique Laporte en History of Shit (1993). En dicho estudio, el autor establece una tensión contradictoria entre la negación de las funciones excrementales ligadas al ano y su necesaria existencia para el sostenimiento del capitalismo. Aunque el trabajo de Laporte apunta principalmente a la necesidad de recuperar el sentido del olfato para oponerse al privilegio contemporáneo de lo visual, su planteamiento acerca de cómo se establecen las instituciones sociales a partir del rechazo y la abyección de lo excremental permite estudiar el carácter subversivo del defecador en el marco de una sociedad obsesionada con la limpieza y la higiene.

Según Laporte, aunque la idea del excremento como un elemento negativo para la sociedad puede rastrearse hasta los primeros edictos que regulaban su tratamiento en el siglo XVI, es solo hasta el surgimiento de la clínica, en el siglo XIX, que empieza a entenderse como una posible amenaza para la estabilidad social y política. En la misma forma en que durante este periodo se renegociaban los espacios públicos y privados, surgió también la necesidad de establecer parámetros para regular la representabilidad de comportamientos que atentaban contra el aparato estatal. En esta demarcación de la conducta a partir de lo performativo, de lo que podía o

bosnia. El autor catalán encontró en la nueva vanguardia y la revolución simbólica propuesta por el grupo de intelectuales franceses a mediados de los años 60 afinidades que le permitieron acercarse a sus principales representantes, con quienes establecería un largo y fructífero intercambio ideológico que puede verse reflejado en sus obras. 
no representarse abiertamente, las funciones corporales debían relegarse a la privacidad. Durante el siglo XX, el evidente desajuste de la racionalidad producido ante la obscenidad de la violencia de las sucesivas guerras mundiales revirtió nuevamente la tensión representabilidad-irrepresentabilidad. La denuncia del defecador consiste precisamente en exponer lo irrepresentable, lo obsceno, y en señalar las inconsistencias de una civilización que ignora el horror de la guerra pero condena al individuo que se opone a que su cuerpo sea controlado.

Para abordar esta problemática, El sitio de los sitios plantea un conflicto entre lo épico y lo anti-épico, con el que Goytisolo busca sensibilizar al lector acerca de las verdaderas dimensiones de la relación entre modernidad y destrucción. Esta realidad, que no es ni puede ser nueva, se detalla en términos de una sintomatología en la que el nuevo orden global aparece representado como una enfermedad:

Los síntomas se acumulaban desde hacía tiempo. Los comparaba a diario a lo largo de sus paseos por el barrio, como preludio sarcástico a ese nuevo orden mundial proclamado por los gurús del poder y la banca: derrumbe social y moral; despidos en masa; sordas explosiones de cólera; ramalazos de locura; proliferación de identidades exclusivas, sectas y bandas; anuncios agoreros de un inminente Apocalipsis. (El sitio 32)

En un contexto místico-religioso, el escritor equipara la situación presente del sitio de Sarajevo con el asedio imaginado del barrio parisino Le Sentier, y a ambos con el Apocalipsis bíblico. ${ }^{12}$

La forma en que se presentan en la novela los síntomas de la enfermedad que desarticula la estructura social revela la existencia latente de un estado de excepción. Para Marco Kunz, el surgimiento de unas nuevas verdades éticas y la prevalencia intervencionista del Estado en la vida pública se soporta en un discurso fascista de limpieza e higiene que lleva a denigrar al

12 El tema místico-religioso es recurrente en la obra de Goytisolo. En Las virtudes del pájaro solitario (1988), por ejemplo, el autor explora la mística de San Juan de la Cruz a través de la imagen del pájaro como representación máxima del estado contemplativo que persiguen tradiciones espirituales árabes como la Sufí. Un acercamiento similar al misticismo musulmán estructura novelas como La cuarentena (1991), en la que la escatología de la tradición árabe cobra un completo protagonismo al proyectar al narrador en un estado de vagabundeo fuera del tiempo que sucede a su propia muerte. Nuevamente, se trata de un homenaje a las tradiciones populares islámicas plagado de referencias al apocalipsis bíblico y a las creencias católicas tan arraigadas en la identidad española. 
otro como un ser enfermo. En el nuevo orden global, el aislamiento y la marginalización surgen como respuestas al miedo de contagio de dicha afección. Como es imposible determinar qué tanto de otro hay en cada individuo, el asedio estatal y la excepcionalidad surgen como soluciones paradójicas que terminan por deteriorar los principios fundacionales de convivencia. Este tipo de respuesta, sin embargo, no es nueva; por el contario, la persecución al otro es un fenómeno antiguo, sistemático y recurrente, como testimonia uno de los personajes de la novela: "mis hermanos y yo revivimos vicisitudes que se remontan a siglos: diásporas, conversiones forzadas, autos de fe, estigmas de infamia, obra de un aguerrido clero matamoros y un populacho de sangre incontaminada cuyo odio al saber y las letras le inducía a enaltecer el analfabetismo como prueba suprema de su herencia ancestral" (El sitio 150). La reversión de los principios de racionalidad que alientan la modernidad no solo se hace evidente en las acciones violentas, sino que además parece provenir de un pasado mítico que para Goytisolo es parte inseparable de la esencia occidental, de su identidad. De ahí que puedan equipararse situaciones como la del sitio de Sarajevo y el pasado español.

Uno de los recursos ficcionales que permite subvertir en la obra la esencialidad identitaria derivada de este determinismo es la inclusión de un elemento onírico que genera ambigüedad y cuestiona la subjetividad. En la tensión sueño-realidad, racionalidad-irracionalidad, Goytisolo permite que las múltiples capas narrativas de su relato desestabilicen el rol del autor -"Todo aquí es escritura! Qué importa que sean o no tus versos..." (El sitio 31) - y que el texto, como tal, sea el objeto a través del cual se legitima la existencia del asedio. En este gesto anacrónico e incluso nostálgico en el que se contraponen autor y texto, y que mira hacia un idealismo estructuralista propio de la literatura de ruptura de mediados de los años 6o, se evidencia la extralimitación de las categorías críticas con las que Goytisolo busca conectar dos situaciones -Bosnia y España- en esencia diferentes. La importancia en la obra de los cuadernos atribuidos al pseudo-santo y profeta Ben Sidi Abú Al Fadaíl, que fueron creados quizás por miembros de la tertulia políglota o reescritos por el comandante de la Fuerza Internacional de Interposición, radica precisamente en que sin ellos la novela no podría existir: no sería posible construir el espacio narrativo que une el sitio de Sarajevo a todos los asedios pasados y por venir ni tendrían cabida los extractos surrealistas que son la consciencia unificadora de todo el texto. Como el propósito de Goytisolo es cuestionar la autoridad y puntualizar la inutilidad de un sistema que no puede garantizar los principios sobre los que esta se instituye, El sitio de los 
sitios es, como señala Antonio Monegal, "a text ruled by indeterminacy and undecidability, in which any possibility of clinging to a truthful or epic narration of war is violently called into question" (37). Si nos suscribimos a esta interpretación, es posible ver cómo el lector queda integrado a un universo de ambigüedad y caos en el que a la carencia de orden se suma la falta de limpieza y belleza, tres condiciones necesarias para la civilización. ${ }^{13} \mathrm{El}$ sitio de Sarajevo se convierte entonces en el lugar donde se destruyen, una a una, las condiciones de la modernidad y donde la ciudad deja de operar como reflejo y memoria de la sociedad -sin memoria no existe un pasado ni un presente y la historia se vuelve circular-.

"Ni calendarios ni relojes! [...] Ayer, hoy, mañana! Olvídese para siempre de esas palabras!" (Goytisolo, El sitio 27), corrobora un personaje del primer sueño relatado en la novela. Bajo el asedio no hay tiempo, o este no es importante, porque el sitio es la repetición eterna de un conflicto que por sus raíces religiosas es irresoluble. En la religión los dogmas son igualmente atemporales, inmutables e incontrovertibles y lo racional no tiene cabida. Se crea así un círculo vicioso, o una falacia circular, que convierte al asedio en causa y consecuencia de la destrucción de los principios de la civilización. Esta imposibilidad de encontrar un orden causal, que ya se había visto en otras obras del autor como Don fulián o Las virtudes del pájaro solitario, se hace presente en la novela cuando los habitantes del barrio parisino Le Sentier intentan encontrar explicaciones y culpables a su difícil situación: "Ayer vi en la tele el arsenal capturado por la policía en el piso de uno de ellos: ametralladoras, fusiles recortados, coranes, cartuchos de dinamita!" (El sitio 46; el énfasis es mío). La inclusión del libro sagrado de la religión musulmana como parte de la lista de armas incautadas por la policía y el hecho mismo de que sea esa la religión que se asocia con el enemigo dentro del nuevo orden global señalan no solo la complejidad, sino también la constancia del conflicto.

Igualmente transhistórica es la tensión aséptico-antiséptico, higienecontaminación, o contagio-aislamiento, opuestos que, en la obra de Goytisolo, como bien ha señalado Abigail Lee Six al estudiar sus primeros trabajos, se revisten de un carácter espiritual: "[Goytisolo] also points to the survival esquizofrenia colectiva in secular society, where the spiritual idea of purity or saintliness become hygiene, and its opposite, impurity or sinfulness become

Para Stanley Black es claro que la participación del lector dentro del propósito trasgresor de la novela es fundamental: "the implication is that the reader experiences something similar, a radical subversion of the rational ability to understand the text" (Fuan Goytisolo 232). 
dirt" (57). La irracionalidad colectiva, entonces, explica el miedo al otro y señala la importancia de que Ben Sidi Abú Al Fadaíl sea presentado en la novela simultáneamente como santo, profeta y defecador. En este personaje convergen las distintas dicotomías que se han señalado aquí y se disuelve el carácter irreconciliable de la oposición entre Oriente y Occidente. Para Goytisolo la concepción utópica de convivencia de culturas propuesta en su momento por Américo Castro, en su estudio de la España medieval es la respuesta para conciliar modernidad y cultura. Sin embargo, las condiciones de control propias de los Estados alineados con el nuevo orden global han creado la necesidad de señalar y rechazar abiertamente al otro. Este proceso de señalamiento, como explica Laporte, es un mecanismo de contrapeso a las continuas reversiones de la civilización: "the repugnant thing has been identified in an argument hazarded against reason-insofar as reason is the mechanism of a State that continually refines its modes of oppression by barricading power behind political knowledge and primitive belief behind positivist technology" (134).

La idea de Laporte plantea nuevamente el problema de la transhistoricidad, ahora enmarcado en el contexto de la limpieza étnica como necesidad homogeneizadora del nuevo orden global. Esta obsesión por la higiene se resemantiza en la abyección y el rechazo de cualquier elemento transgresor, aspecto que es inmediatamente transferido del imaginario abstracto al espacio concreto de la mirada. En medio de las ansiedades producidas por lo heterogéneo, el flâneur se desplaza del simple voyeurismo a una contemplación mucho más mística y pesimista del deterioro o destrucción de los valores sociales de tolerancia y respeto a la individualidad. El defecador, profeta y visionario, es presentado en la novela como ese transeúnte que advierte la fragilidad de la civilización: "Su excitación de años atrás, cuando recorría el barrio con curiosidad insaciable, a la caza de sensaciones y aventuras, había cedido paso a una premonición más pesimista y cruda: el gueto, la guerra interétnica de los guetos, reemplazaría con su brutalidad y tribalismo a la concepción ideal de la cives como crisol de culturas" (El sitio 36 ). El concepto de una cives en la que todos los ciudadanos comparten la protección del Estado se desarticula en la regresión de la ciudad sitiada a una etapa casi tribal en la que la identidad depende de vínculos estrictamente biológicos. A este respecto, entonces, la novela presenta dos lecturas y dos paradigmas epistemológicos y teológicos que, como identifica Manuel Ruiz en su estudio sobre la obra, se sintetizan en la tensión Oriente-Occidente: "la primera, signo generado de Europa (París) -la cultura judeo-cristiana occidental-; la 
segunda, del Magreb (Marraquech) -el ámbito cultural árabe-. Esta dualidad textual dialógica repite el diseño binario sobre los propios textos: los dos manuscritos de las dos ciudades" (35). El contraste entre Sarajevo y París, y entre la novela de Goytisolo y los metarrelatos que la conforman, evoca en su ambigüedad la necesidad de recuperar la ciudad como el lugar de lugares: el espacio de la tolerancia y el mutuo enriquecimiento cultural que da significado a la metáfora del crisol de razas que defendía Américo Castro.

La realidad que expone la novela, sin embargo, es muy distinta. El fuego que alimenta el crisol se ahoga en el sentimiento permanente de sospecha que cunde en la sociedad globalizada - un deseo de señalar diferencias y de establecer la pertenencia a través de la exclusión-. La idea de que el Estado moderno no logra garantizar la protección de sus ciudadanos lleva a la creación de organismos para-estatales que ejercen la justicia bajo parámetros propios, derivados generalmente de la percepción colectiva del otro como una amenaza. En el sitio del barrio Le Sentier este proceso queda completamente ejemplificado: "Las cosas han llegado a un punto inadmisible! Si las autoridades no intervienen, tendremos que actuar por nuestra cuenta: tomarnos la justicia por las manos!"' (El sitio 45-46). En medio del desconcierto y la incertidumbre de no lograr identificar la enfermedad que está deteriorando la sociedad, el otro aparece como la explicación más obvia: "A falta de pruebas concretas y argumentos sólidos, las hipótesis y sospechas se centraban en torno a la composición heterogénea [...] del barrio" (El sitio 71). ${ }^{14} \mathrm{El}$ otro se vuelve el enemigo mortal con el que Goytisolo universaliza el tema de la violencia, metaforizando la idea de que el mayor enemigo de la civilización es la civilización misma.

Como ha señalado Kristeva, el discurso discriminatorio fundado en el temor al otro como reflejo de la condición heterogénea del sujeto facilita la construcción de la identidad a través del contraste. Una forma de negociar la tensión entre higiene y contaminación es haciendo evidente la existencia de lo abyecto en una sociedad en la que civilización es sinónimo de limpieza. La higiene sirve entonces para señalar diferencias, para crear la contraposición entre lo civilizado y lo bárbaro. Esta es otra de las razones por las que el defecador es una figura central en la novela. Precisamente en su crítica a los estamentos de poder "destaca la insólita lección de humildad de defecar en

14 En su texto sobre la migración en la obra de Goytisolo, Marco Kunz recuerda el episodio del ayuntamiento del Ejido, donde la violencia desatada en febrero de 2000 demostró que "basta un pretexto para desencadenar la violencia xenófoba" $(60)$. 
público como muestra suprema de la igualdad de las criaturas y su sumisión al orden universal del Cosmos" (El sitio 141). Así, más allá del asedio a la individualidad, se critica la estructura social de discriminación y abuso en la que el otro ocupa el lugar más bajo, al ser el excremento, el residuo del proceso digestivo de la sociedad:

[...] a las víctimas del dogma científico del monetarismo, tienda global y especulación sin traba, a la masa de detritos humanos reciclables, que pronto serían exportados en contenedores al Tercer Mundo para salvar el ecosistema del primero y frenar su degradación ambiental; [...] a los excrementos del cuerpo social que, luego de ser comprimidos y triturados en el estómago e intestino de los poderosos, caían en las letrinas por el despeñadero del recto. (El sitio 48 )

El lenguaje de lo abyecto se relaciona aquí con el sufismo islámico y las utopías socialistas; ambos, intentos subversivos de buscar la igualdad a través de la visibilidad: el primero en lo social y el segundo en lo espiritual (Kunz 222). En contraste, la sociedad del nuevo orden exige la invisibilidad de lo sucio y, en general, de lo heterogéneo. ${ }^{15}$

Las estrategias con las que la sociedad occidental busca borrar los rasgos de heterogeneidad están cargadas en cualquier caso de ambigüedad. Estas inconsistencias evidencian la necesidad de reafirmar el control estatal sobre el cuerpo para eliminar lo excremental, y por tanto contaminante, del espacio público: "To this very day, civilization's ambivalence toward shit continues to be marked, on the one hand, by a will to wash those places where garbage collects (i.e., in city and speech) and, on the other, by a belief in the purifying value of waste-so long as it is human" (Laporte 37). La importancia de lo corporal aparece reflejada en la novela en la representación de la ciudad como un cuerpo enfermo y deteriorado. Así, Goytisolo describe "viviendas desdentadas, desfiguradas o tuertas" (El sitio 57) que son evidencia de la aniquilación de todo un sistema de valores. Este aspecto también puede verse como un síntoma de la destrucción del yo, que a través del giro autobiográfico

15 La crítica a la civilización occidental teniendo al cuerpo como referencia puede trazarse a obras anteriores a El sitio de los sitios. Es por eso que el análisis de Abigail Lee Six resulta pertinente, en tanto logra identificar que en la obra de Goytisolo "the reader is reminded of the equally laughable presence [of a] Western Society, which demands that respectable people behave as though they did not perform bodily functions nor possess the organs with which to do so" (98). 
busca señalar un carácter paradójico y ambiguo de la modernidad que solo puede resolverse en la escritura. ${ }^{16}$ La imagen del defecador y en general la presencia del excremento completan así la representación incoherente de una supuesta civilización occidental; en las palabras de Epps, es "[i]n shit, [that] the tenuous ties of cleanliness and godliness are sullied, the scandal of productivity is unleashed, and the underside of (im)purity and ir(rationality) is forcefully exposed" (165). Una vez desarticuladas las categorías sobre las que se sustenta el nuevo orden global, las transgresiones de lo privado se convierten necesariamente en objetos políticos.

La capacidad de subversión del excremento queda completamente reafirmada en la idea de Hocquenghem de que el ano no puede existir en lo público, lo cual hace que la defecación sea la última actividad sobre la que el Estado puede ejercer control. Goytisolo es consciente del proceso de pérdida de individualidad que hace del sujeto una víctima de la tiranía del poder. ${ }^{17}$ Esta visión apocalíptica de la realidad queda ejemplificada en el defecador, que, siendo también santo y profeta, da completo sentido a la palabra escatología. Además de la capacidad subversiva en lo religioso y en lo moral, el defecador propone la inclusión del otro en la construcción de la identidad: "Excrement and its equivalents (decay, infection, disease, corpse, etc.) stand for the danger to identity that comes from without: the ego threatened by the non-ego, society threatened by its outside, life by death" (Kristeva, "Powers" 260). En términos sociales, cualquier elemento foráneo que pone en riesgo la higiene del sistema capitalista es, como el defecador, un "detrito irreciclable en el circuito de la productividad" (El sitio 34 ).

Respecto a la producción de capital y al sentido utilitario del recurso humano, la noción de propiedad convierte al defecador en un foco de rebelión. Debido a que la sociedad ha anulado sus derechos fundamentales, el grito libertario de este personaje es un reclamo de visibilidad para el otro

16 Es importante señalar que a través de la escritura Goytisolo consolida su propia identidad: "La escritura es entonces el lugar de una subjetividad recuperada, que ya no será la del autor como propietario de sus obras ni la de autobiógrafo, sino la de escritor" (Topuzian 608).

17 Para Goytisolo uno de los mayores problemas de la sociedad actual "es la negación de los apetitos o realidades corporales en nombre de ideologías políticas o religiosas, que abstraen al ser de carne y hueso y lo someten a la opresión alienadora de alguna finalidad trascendente u omnímoda. Convertido en 'cuerpo glorioso' (campo de batalla de demonios y ángeles) o simple instrumento productivo (al servicio de la acumulación capitalista burguesa o de la tecnoburocracia postestalinista) el hombre deviene así un robot o zombi [...] presa fácil por tanto de todas las tiranías" (citado en Epps 235). 
y una denuncia del deterioro causado por el nuevo orden global: "Sí, estoy cagando! Miren bien toda esta mierda! Es mía y bien mía! Nadie puede impedirme cagar! Es el único derecho que me queda!" (El sitio 38). El reclamo del defecador, además, no puede representar un caso aislado o un esfuerzo individual; el profeta del excremento es consciente de la necesidad de integrar a todo el residuo social para formar un grupo sin distinciones raciales o religiosas que, unido por esta imagen escatológica, represente al otro. Una especie de socialismo primitivo articula lo que el defecador va a llamar, en alusión clara al Partido Socialista, la Internacional del excremento:

Nosotros componemos la Internacional de los excrementos, las heces apestosas del nuevo orden planetario! [...] Nuestra marea hedionda invadirá sus calles, avanzará irresistible como la lava de los volcanes, paralizará el tráfico de sus automóviles, enviscará la acera a sus atildados ejecutivos, cercará el sagrado templo de la Bolsa y silenciará el griterío de sus adoradores, llenará de fetidez sus mansiones y ahuyentará de ellas a sus habitantes, se extenderá en las oficinas bancarias hasta alcanzar las cajas de caudales y transmutar el oro y billetes en mierda! (El sitio 49)

Como acción revolucionaria, el acto de defecar se constituye en un ataque contra la civilización (Ruiz 163). Dos elementos resaltan entonces del defecador como agente de subversión: en primer lugar, la destrucción de las distinciones entre lo público y lo privado, que opera como una denuncia de los alcances del poder y de sus políticas para el sostenimiento del sistema capitalista; y, en segundo, la condición de abyección que permite relacionar el acto de transgresión del profeta con el miedo al otro. ${ }^{18}$ De esta manera, el acto de liberar el excremento sirve de metáfora para señalar que aquello que mayor rechazo nos causa es producido por nosotros mismos, que el odio hacia el "otro" es, en realidad, un odio primitivo del ser humano contra el ser humano. Se anticipa así, de forma profética, que la guerra y el asedio se repetirán indefinidamente dentro de un nuevo orden global en que se privilegian los espacios homogéneos, higiénicos y asépticos.

Otros aspectos que suelen ser tópicos en la novelística de Goytisolo, como la masturbación o la homosexualidad, aparecen también en El sitio de

18 Para Julia Kristeva, el asco que genera lo abyecto es un espacio de absoluta abstracción que, sin embargo, impacta creando una conciencia particular: "A 'something' that I do not recognize as a thing. A weight of meaninglessness, about which there is nothing insignificant, and which crushes me" ("Powers of horror" 96). 
los sitios relacionados con la abyección, la subversión y la inconformidad. En forma de poemas apócrifos, el uso de estas imágenes dentro del texto se hace "in the light of rebellion against authority" y constituyen, como había identificado Abigail Lee Six en trabajos anteriores del autor, "a defiant statement of the potential pleasure rooted in the self" (6o). La recuperación de la individualidad a través del placer resulta contradictoria si se piensa que las metáforas de abyección del yo que usa Goytisolo son poesía cargada de belleza lírica. Esta posición contradictoria es una forma más de criticar los contrastes entre las ideas de orden e higiene de la civilización occidental y el horror del asedio. La contraposición se hace más específica en la comparación entre el sitio de Sarajevo y algunos aspectos de la historia de España. El supuesto pasado de convivencia religiosa de la España medieval, por ejemplo, aparece como una realización contemporánea en Sarajevo: "Sarajevo es una mezcla: multicultural, muticonfesional, multinacional [...] la sinagoga está a un paso de la mezquita y ésta a un paso de las iglesias católica y ortodoxa" (Cuaderno 61). De la misma forma, se reproduce la intolerancia y su resultado más nefasto: la guerra -"como en España en 1936, declararon la guerra a su pueblo y se cubrieron con la sangre inocente de sus paisanos" (El sitio 128)-. Goytisolo inventa el sitio del barrio Le Sentier con el objetivo de mostrar que existe un patrón en Europa, que lo que ocurre en Bosnia ya había pasado en España y se puede repetir en cualquier otra ciudad en la que se estigmatice la heterogeneidad cultural, racial o religiosa.

Goytisolo contrapone la importancia de la memoria a la destrucción deliberada del pasado para subrayar que la civilización occidental busca ocultar los errores que ha repetido y seguirá repitiendo en nombre del progreso, "esta barbarie programada cuyo fin era barrer la sustancia histórica de una tierra para montar sobre ella un edificio compuesto de patrañas, leyendas y olvidos" (Cuaderno 57). La idea de guerra justa y el posterior memoricidio son solo pretextos contradictorios que banalizan el conflicto como instrumento de la civilización. A nivel ideológico esta tensión se resuelve en la novela mediante un posicionamiento político claro: Goytisolo sigue una estricta agenda anticapitalista y antioccidental (Ribeiro 119). En el nivel formal, la obra subvierte la historia mediante el uso de distintas estrategias narrativas, poniendo en duda la separación entre realidad y ficción. En un intento por alejarse de cualquier representación épica que lo vincule con el mismo sistema que avala el sitio, Goytisolo conjuga la historia, el periodismo, el cine y la televisión, y en El sitio de los sitios crea una especie de antiutopía, un otro de la visión idealizada de convivencia y tolerancia de un pasado en el que él cree. 
El discurso de ruptura que se deriva de este mecanismo ficcional muestra la imposibilidad de distinguir entre la historia real y la historia oficial; como señala en la novela un miembro de la tertulia políglota: "Cuanto material histórico llega a nuestras manos es puro celestinaje, tráfico y manipulación" (El sitio 101-102). Esto explica que en la novela prevalezca la ambigüedad y que la compleja estructura del texto cuestione permanentemente la idea de autor mediante la falsificación y la transformación. Sin embargo, como se explicó, esta aproximación simbólica resulta problemática al intentar acercar dos realidades disímiles: España y Bosnia.

La denuncia de Goytisolo en El sitio de los sitios se convierte entonces en un llamado desesperanzado ante la inevitable posibilidad de futuros asedios, de que subsista la barbarie y de que la guerra interétnica retorne como respuesta a los intentos contradictorios del nuevo orden de crear comunidades globales en donde se ignora el pasado y se pasa por alto el carácter transhistórico de las diferencias religiosas. En ese sentido, el sitio de Sarajevo es el rostro del otro que Europa rechaza al mirarse en el espejo de la civilización. Por esto, el defecador es la perfecta tipificación de todas las negaciones, es la evidencia de que al interior de la civilización no importan las diferencias puesto que todo es abyección, rechazo y violencia. La gran falla de la modernidad subyace por tanto en el intento homogeneizador que deviene en obsesión por la limpieza, en la negación progresiva de la individualidad mediante la creación de aparatos de poder y vigilancia que, paulatinamente, aniquilan la posibilidad de que exista la individualidad.

Finalmente, el defecador representa también un intento contestatario al control y la regulación, una búsqueda de subjetividad que se señala en la obra mediante la ausencia de un autor y un original. Pese al carácter de denuncia de la obra, sin embargo, "Goytisolo's texts are not unequivocally liberational; indeed, many of them repeat and reinforce some of the most entrenched tactics and ideas of the dominant order" (Epps 9). Este aspecto queda resaltado en la novela en la condición ambigua de observador que el autor asume en Sarajevo y con la cual busca crear una conciencia participativa para promover un cambio que de antemano sabe imposible: "La experiencia nos ha enseñado que ningún progreso de la civilización es durable, que el exclusivismo e intolerancia la minan por dentro, que pogromos y limpiezas étnicas se repiten" (El sitio 151). Igualmente, la defensa y exaltación de lo marginal que propone la novela se ve cuestionada al quedar envuelta en la dialéctica centro-periferia propia del rol que jugó Goytisolo como principal corresponsal del conflicto para el medio impreso de mayor difusión en España, papel que aprovechó 
para reiterar, mediante complejas analogías, sus denuncias del fundamentalismo identitario peninsular, pero que lo llevó a convertirse inopinadamente en agente de la homogeneización que en principio estaba rechazando. Es en este panorama pesimista que quizás sea necesaria la invención de un profeta, de un santo, de un transgresor, que al igual que el defecador, el pseudo Ben Sidi Abú Al Fadaíl, reviva las esperanzas de que todavía no se haya alcanzado, como dice Goytisolo en la nota con la que cierra la novela, "el límite final de la literatura" (El sitio 183).

\section{Obras citadas}

Black, Stanley. Fuan Goytisolo and The Poetics of Contagion: The Evolution of a Radical Aesthetic in the Later Novels. Liverpool: Liverpool UP, 2001. Impreso.

Black, Stanley. "The Author as Hero in the New World Order: The Power of Fictionality in Goytisolo's El sitio de los sitios". Heroism and Passion in Literature:

Studies in Honor of Maya Longstaffe. New York: Graham Gargett, 2004. 233-244.

Epps, Bradley. Significant Violence: Oppression and Resistance in the Later

Narrative of Juan Goytisolo. Oxford: Oxford UP, 1996. Impreso.

Goytisolo, Juan. Cuaderno de Sarajevo: anotaciones de un viaje a la barbarie. Madrid: El País - Aguilar, 1993. Impreso.

Goytisolo, Juan. El sitio de los sitios. Madrid: Alfaguara, 1995. Impreso.

Gunn, Joshua. "ShitText: Toward a New Coprophilic Style". Text and Performance Quarterly 26.1 (2006): 79-97. Impreso.

Hardt, Michael and Antonio Negri. Empire. Cambridge: Harvard UP, 2001. Impreso.

Hierro, Manuel. "La memoria sitiada de Juan Goytisolo en El sitio de los sitios". Antípodas: Fournal of Hispanic and Galician Studies 8-9 (1996-1997): 144-154. Impreso.

Hocquenghem, Guy. Homosexual Desire. Trans. Daniella Dangoor. Durham: Duke UP, 1993. Impreso.

Kristeva, Julia. "Powers of Horror: An Essay on Abjection". The Portable Kristeva. Ed. Kelly Oliver. New York: Columbia UP, 1997. 229-263.

Kristeva, Julia. "Strangers to Ourselves". The Portable Kristeva. Ed. Kelly Oliver. New York: Columbia UP, 1997. 264-294. Impreso.

Kunz, Marco. Juan Goytisolo: metáforas de la migración.

Madrid, Verbum, 2003. Impreso.

Laporte, Dominique. History of Shit. Trans. Nadia Benabid and Rodolphe el-Khoury. Cambridge: MIT Press, 2000. Impreso.

Monegal, Antonio. "Aporias of the War Story". Spanish

Cultural Studies 3.1 (2002): 29-41. Impreso. 
Pérez, Genaro J. “La cuarentena y El sitio de los sitios de Juan

Goytisolo: intertextualidad, creación y recreación autorial".

Letras Peninsulares 14.3 (2001-2002) 391-403. Impreso.

Ribeiro de Menezes, Alison. Fuan Goytisolo: The Author as

Dissident. Woodbridge: Tamesis, 2005. Impreso.

Ruiz Lagos, Manuel. Lector apud Goytisolo: las paradojas del texto hermético, sobre El sitio de los sitios. Sevilla: Guadalmena, 1996. Impreso.

Six, Abigail Lee. Fuan Goytisolo: The Case for Chaos.

New Haven: Yale UP, 1990. Impreso.

Topuzian, Marcelo. "El autor de los últimos textos de Juan Goytisolo". Actas del XIV Congreso de la Asociación Internacional de Hispanistas. Ed. Robert Nival, Isaías Lerner y Alejandro Alonso. Newark: Cuesta, 2004. 605-61o. Impreso. Virilio, Paul. City of Panic. Trans. Julie Rose. New York: Berg, 2005. Impreso. 